\title{
Editorial
}

\section{Ética, Moral e Saúde Coletiva}

| Kenneth R. de Camargo Jr. I

Abordagens tradicionais de uma saúde pública subordinada ao modelo biomédico, da mesma forma que as concepções de ciência que a embasam, tendem à visão tecnocrática, supondo considerações sobre valores, por exemplo, como fora de seu escopo. Ora, valores não são estranhos à ciência e muito menos à saúde; é impossível pensar em alguma esfera da experiência humana onde toda sorte de valores, afetivos, morais, éticos, individuais e coletivos não estejam presentes e desempenhem papel fundamental.

O tema da presente edição, selecionado a partir dos artigos de demanda espontânea, apresenta um conjunto de estudos nos quais a questão dos valores ocupa espaço fundamental, sendo abordados numa perspectiva crítica. Alguns desses artigos são inovadores tanto na temática quanto na abordagem, e oferecem uma contribuição fundamental ao pensamento crítico na Saúde Coletiva.

O tema inicia-se pelo trabalho de Alzuguir, que analisa a carreira moral de tratamento do alcoolismo em um serviço público de saúde a partir de depoimentos de homens e mulheres "alcoólatras", apoiando-se em Goffman. Leite e Henriques comparam as legislações ou guias de referências em reprodução humana assistida de diferentes países, apontando para importantes diferenças atribuíveis, entre outros aspectos, a perspectivas religiosas. Melo desenvolve o argumento que a atividade médico-pericial relativa ao auxílio-doença envolve um risco específico ligado à tarefa de controle, incorrendo em riscos morais.

Abrindo a seção de temas livres, Lima e Brasil identificam o impacto do Programa de Volta para Casa para a efetivação das ações de desinstitucionalização no âmbito da Saúde Mental. Batista et al. apresentam os resultados de estudo sobre a imagem corporal de pessoas que tiveram hanseníase e que desenvolveram incapacidades físicas, com base no teste psicológico Desenho da Figura Humana (DFH), com ênfase na análise interpretativa das mãos e dos pés, locais mais 
afetados pela doença. Santos e Nunes descrevem o conhecimento em saúde mental construído pelo Agente Comunitário de Saúde (ACS), concomitante à produção de cuidado na mesma área.

Moraes et al. investigam as dimensōes mais valorizadas pelos usuários na APS, com base em grupos focais. Libanio et al. analisam as repercussōes da integração das atividades de controle do vetor da dengue no município de PiraíRJ com as ações da Estratégia de Saúde da Família, em particular, com os ACS, sujeitos principais das últimas. Soares e Trad apresentam resultado de estudo etnográfico sobre os sentidos atribuídos aos discursos veiculados no campo social sobre alimentação e nutrição por cuidadores domiciliares de crianças.

Riquinho e Hennington discutem as dificuldades e potencialidades ligadas à diversificação agrícola e substituição ao cultivo do tabaco, com base em estudo etnográfico envolvendo representantes do Estado, da sociedade civil e da própria indústria em região produtora do sul do Brasil. Belardo trata da forma como a ciência biomédica constrói uma maneira de "olhar" e definir os problemas sociais, a partir da produção do conhecimento científico sobre uma doença infantil (síndrome hemolítico-urêmica) na Argentina. Arreguy estuda o problema da violência nas escolas a partir do olhar da psicanálise.

Quinderé et al. discutem as interaçôes entre os diferentes níveis de complexidade do sistema de saúde na atenção à saúde mental e a conformação da rede de atenção à saúde mental no município de Sobral-CE. Martins e Iriart analisam o itinerário terapêutico de pessoas com hanseníase a partir de uma perspectiva socioantropológica. Encerrando a seção, Rodrigues e Peixoto Jr. analisam as concepçôes de Saúde e Doença presentes na obra de Winnicott e Canguilhem.

$\mathrm{Na}$ seção de resenhas, Maksud nos apresenta a coletânea Estigma e Discriminação: desafios da pesquisa e das políticas públicas na área da saúde, organizada por Monteiro e Vilella. 